\title{
Social immunity as a source of sustainable development of the regional economy
}

\author{
Julia Myslyakova \\ Ural State University of Economics, 8 Marta Str., 62, 620144 Ekaterinburg, Russia
}

\begin{abstract}
At present, the problems of sustainable economic development still remain relevant for many regions. This research presents the idea that the stability of the territorial economy and the socially safe state of society are interrelated. The hypothesis was formulated that social immunity of the region is one of the sources of its sustainable economic development. To prove this hypothesis the following tasks were solved: social immunity assessment methodology was developed; the methodology was tested on the territories of the Ural region; the dependence of the territorial sustainable development on its social immunity was revealed. The methodology allows us to model the core of social immunity of any territory. It is based on the Frobenius norm, which reflects both positive and negative transformations of society. Approbation of the methodology for assessing social immunity was carried out on the example of the Sverdlovsk, Kurgan, Chelyabinsk and Tyumen oblasts during 2010-2018. The research made it possible to prove the hypothesis and to conclude that lack of social immunity in the region leads to poor economic effects received by business entities and the territory's susceptibility to economic destabilizing external impacts, which are both random and systematic.
\end{abstract}

\section{Introduction}

At present, the concept of "immunity", which comes from medicine and means the body's defense mechanism opposing external and internal pathogens, is increasingly used in various scientific fields. This term can be found in legal, social, economic and other studies of society life. One of the most interesting research areas is the social immunity of the territory, meaning society's ability to withstand external social risks and threats caused by infiltration of values, norms, behavioral patterns of other cultures into society, which may destroy its integrity, integration and adaptive potential. At the same time, the opposition to risks occurs through formation of a protective mechanism, which is responsible for the immunity to external impacts on society and the preservation of stability and high adaptability of the internal environment.In this context of understanding immunity of society, its value functions are: protection and opposition of society to exogenous negative impact; adaptation of the population to the external environment; integration and preservation of the integrity of society in the conditions of its unbalanced development. According to T. Parsons and N. Luhmann, social immunity serves as a source of maintaining a stable state of the regional system and its society and contains the necessary 
measures to support the solution of current problems, ensuring the functioning of the territorial system with its inherent efficiency [1].

Many authors also note that social immunity of the regional system arises under the influence of active social institutions, as a response of the territory to imbalances in spatial development and new global challenges. In this context, immune system of society is presented as a complex of people's psychological factors such as social orientations, traditions, values and attitudes, adherence to national ideas, patriotism, etc. That is why the sources of its development are influenced by the general psychological mood of society, propaganda of socially significant priorities, involvement in active political activities, etc. Another interesting aspect of understanding social immunity is presented in the ideas of the organismic theory representatives. The theory founder, Lorenz von Stein, understood society as a cultural organism in which all its parts influence and complement each other only through the interaction of the economy, state and society. Sudden processes of social transformation can be compared with an organism's reaction to a painful external influence, which leads to disruption of usual rhythms of the organism's functioning [2].Taking into account this scientific philosophical meaning of the definition, it is possible to classify social immunity into innate and acquired, and social hardening and social vaccination are measures to support and strengthen it.Representatives of social economy, R.S. Greenberg and A. Ya. Rubinstein, understand social immunity as the mechanism for identifying society interests, regardless of the state current position [3]. Another aspect of understanding social immunity is presented in the works of E. Erickson, M. Predovskaya and I. Mazurenko et al., who consider it as a protective belt that allows a country to preserve its identity, uniqueness of its own culture, history, political and economic sovereignty [4].

Having analyzed the presented interpretations of the definition under study, we believe that social immunity of the regional system in the economic context is responsible for the territory's ability to withstand potential risks of external and internal shocks. It also creates conditions for systemic recovery after destructive events, due to the presence of internal resources and assets that have not been involved previously [5, 6.7]. An important function of this immunity is to focus the region on creating sustainable dynamically competitive advantages with extrapolation into the future as well as on the ability of an economic entity to neutralize potential threats and get out of extreme situations with minimal losses by adapting in the present situation to signals and challenges. This understanding of social immunity allows us to conclude that it is responsible for the hereditary degree of immunity, protection of society against unfavorable factors and endows society with the necessary set of properties, which all together present the potential for sustainable economic development. The author's understanding of the research basic definition serves as a premise for formulating a scientific hypothesis that social immunity of the region is one of the sources of sustainable development of its economy. To prove the hypothesis, we set the following tasks:

- to develop the methodology for assessing social immunity;

- to test the methodology on the Ural region territories;

- to reveal the interrelation between social immunity of the Ural territories and sustainable development of their economy.

\section{Materials and methods}

Our research method is based on the understanding that the region retains social immunity as long as the dynamics of positive trends and changes in the society in the territory under consideration exceeds the dynamics of its negative trends. In addition, since we consider social immunity as a source of sustainable economic development, its elements should have 
a direct impact on this dynamic state. According to A. Aganbegyan, T. Zaslavskaya, Z. Kalugina, the regional economy develops steadily when three basic social conditions are met [8].

1. Existing trends in intellectual and cultural development of people living in the region stimulate the production potential of society.

2. People's basic needs for consumption and employment on a scale that maintains a high level of economic productivity are met.

3. Stable population corresponding to the productive capacity of the economy and sufficient to ensure a high quality of life in society is maintained.

These conditions for sustainable economic development determine the choice of certain social immunity assessment parameters, which reflect the influence of the state of society on the processes taking place in the region economy:

- preservation of public health, expressed through the potential of public well-being. This indicator reflects the dynamics of life expectancy reduction, mortality increase, especially at working age, number of people with chronic diseases increase [9]. Negative changes in the field of ensuring public health indicate of transformations in socio-economic conditions of human life and signal of a threat to the safety of regional reproduction and accumulation processes;

- activation of the labor potential, including raising education level and involving people in the innovation sphere. P. Romer, who spoke about that in his works, argued that to achieve sustainable growth of GRP it is necessary to invest in education of the population as well as in population growth and labor productivity stimulation [10];

- stabilization of the population economic potential means strengthening the level of GRP per capita; fixing employed population in production processes and maintaining a high level of income, which determines consumption processes at the regional level.

The above mentioned assessment parameters of social immunity form the basis of the toolkit for proving our hypothesis. The author's method for assessing social immunity involves the following sequence of steps.

1. Identification of assessment indicators. On the one hand, these indicators should relate social processes to the transformation of economic development trends; on the other hand, they should meaningfully reflect the dynamics of change and, at the same time, be dimensionless.

To fulfill these two conditions, we propose to reveal the potentials indicated above through indices. The calculation of each potential is obtained by the ratio of the considered parameter in the current time period to the indicator of the previous period. The use of indices for a current time period by averaging its value will make it possible to draw more accurate conclusions when analyzing social immunity. These structural parameters of social immunity have the morphology shown in Table 1.

Table 1. Parameters and indicators of the region social immunity

\begin{tabular}{|l|l|}
\hline Parameter & Indicator \\
\hline Public well-being potential (P_health) & Natural population growth rate (P_health_1) \\
\cline { 2 - 2 } & Total fertility rate (P_health_2) \\
\cline { 2 - 2 } & Population morbidity rate (P_health_3) \\
\hline Public labor potential (P_labor) & Employment-to population ratio (P_labor_1) \\
\cline { 2 - 2 } & Tertiary education attainment rate (P_labor_2) \\
\cline { 2 - 2 } & R\&D personnel headcount index (P_labor_3) \\
\hline $\begin{array}{l}\text { Public economic potential } \\
\text { (P_economy) }\end{array}$ & GRP per capita (P_economy_1) \\
\cline { 2 - 2 } & Average annual employment rate (P_economy_2) \\
\cline { 2 - 2 } & Average per capita income (P_economy_3) \\
\hline
\end{tabular}


Modeling the core of the region social immunity, which has a matrix format "A" in our case, will be carried out according to formula 1, its elements being public potentials of the territory, which integrate all current social trends of its functioning changes and influence the economy dynamics:

$$
\mathrm{A}=\left|\begin{array}{ccc}
P_{-} \text {health_1 } & P_{-} \text {health_2 } & P_{-} \text {health_3 } \\
P_{-} \text {labor_1 } & P_{-} \text {labor_2 } & P_{-} \text {labor_3 } \\
P_{\text {ecconomy_1 }} & P_{-} \text {economy_2 } & P_{-} \text {economy_3 }
\end{array}\right|
$$

To determine the social immunity core size we suggest using Frobenius norm, which reflects both positive and negative society transformations (formulas 2, 3 и 4):

$$
\begin{aligned}
& \qquad A^{+} \|=\sqrt{\sum_{i=1}^{m} \sum_{j=1}^{n} a_{i j}^{2}} \text { at aij }>0, \\
& \left\|A^{-}\right\|=\sqrt{\sum_{i=1}^{m} \sum_{j=1}^{n} a_{i j}^{2}} \text { at aij }<0, \\
& \text { Social_immunity }=\left\|A^{+}\right\|-\left\|A^{-}\right\|,
\end{aligned}
$$

where Social_immunity is social immunity core of the territory,

$\left\|A^{+}\right\|$- positive norm,

$\left\|A^{-}\right\|-$negative norm,

aij-elements of matrix A.

The resulting model of the social immunity core can be applied to any territory level. It is universal and reflects society's ability to resist random impacts, be protected by its endogenous factors and maintain/keep stagnant economic development.

\section{Results and discussion}

The analysis of social immunity was carried out on the territories of the Ural region (the Kurgan, Sverdlovsk, Chelyabinsk and Tyumen oblasts) during 2010-2018. According to the indicator of "public well-being potential", we drew conclusions that the natural population growth index and the total fertility rate index in all the territories under consideration had negative dynamics over the whole time period. The Sverdlovsk and Chelyabinsk oblasts demonstrate the most deteriorating trends of the natural growth rate. The population morbidity rate is stable in the territories of the Ural Federal District, except the Chelyabinsk oblast (table 2). Public well-being potential shows negative dynamics according to all assessment indicators in the Chelyabinsk oblast.

Table 2. Public well-being potential in the Ural Federal District territories in 2010-2018

\begin{tabular}{|l|l|l|l|}
\hline Ural Federal District & P_health_1 & P_health_2 & P_health_3 \\
\hline Kurgan oblast & -0.0831 & -0.02618 & 0.011155 \\
\hline Sverdlovsk oblast & -0.51071 & -0.01669 & 0.00151 \\
\hline Chelyabinsk oblast & -0.40952 & -0.02248 & -0.00293 \\
\hline Tyumen oblast & -0.02252 & -0.01983 & 0.03339 \\
\hline
\end{tabular}

Also, most territories record a decrease in employment-to population ratio, which negatively affects the economic processes in the Ural region (Table 3). Only the Chelyabinsk oblast showed a positive trend of tertiary education attainment rate during the entire period of the study. The worst dynamics of this indicator is recorded in the Kurgan oblast. The index of the number of personnel engaged in R\&D is stable in the Ural region, 
with the exception of the Kurgan oblast, where its stagnation is observed. The Chelyabinsk oblast labor potential has the best dynamics and is positively sustainable.

Table 3. Public labor potential in the territories of the Ural Federal District in 2010-2018

\begin{tabular}{|l|l|l|l|}
\hline Ural Federal District & P_labor_1 & P_labor_2 & P_labor_3 \\
\hline Kurgan oblast & -0.00956 & -0.15182 & -0.00361 \\
\hline Sverdlovsk oblast & -0.00856 & 0.006601 & 0.001294 \\
\hline Chelyabinsk oblast & 0.00169 & 0.045752 & 0.006053 \\
\hline Tyumen oblast & -0.00752 & 0 & 0.012165 \\
\hline
\end{tabular}

The economic potential of the population in the Chelyabinsk and Tyumen oblasts is stable, in contrast to other territories under consideration (Table 4). According to the Employment-to population ratio the Kurgan oblast records a decrease in growth rates, which is due to internal labor migration. A similar dynamics is typical for the Sverdlovsk oblast. In the near future, a further downward trend is expected, since our sociological surveys conducted among young people allow us to note the high interest of university graduates in finding employment in metropolitan regions and European countries.

Table 4. Public economic potential in the territories of the Ural Federal District in 2010-2018

\begin{tabular}{|l|l|l|l|}
\hline Ural Federal District & P_economy_1 & P_economy_2 & P_economy_3 \\
\hline Kurgan oblast & 0.091398 & -0.01991 & 0.053602 \\
\hline Sverdlovsk oblast & 0.10837 & -0.00805 & 0.065796 \\
\hline Chelyabinsk oblast & 0.120007 & 0.002503 & 0.061295 \\
\hline Tyumen oblast & 0.102213 & 0.003604 & 0.06122 \\
\hline
\end{tabular}

The Sverdlovsk oblast has the best growth rate of the average per capita income of the population, thanks to its employment, including jobs provided by small and medium-sized businesses and to the strategy for diversifying the sectoral structure of the territorial economy. All this also testifies to the presence of innovative facilities, creation of new jobs, as well as the launch of industrial modernization processes of functioning industries.

The obtained matrices norms illustrate that the Tyumen oblast possesses hidden nuclear forces, since the strength of positive trends taking place in society in this territory significantly exceeds the strength of negative dynamics (Table 5).

Table 5. Social immunity in the territories of the Ural Federal District in 2010-2018

\begin{tabular}{|l|l|l|l|l|}
\hline $\begin{array}{l}\text { Ural Federal } \\
\text { District }\end{array}$ & A+ & A- & Social_immunity & GRP index \\
\hline Kurgan oblast & 0.106541472 & 0.176464158 & -0.069922686 & 0.080 \\
\hline Sverdlovsk oblast & 0.126967482 & 0.511121949 & -0.384154467 & 0.109 \\
\hline Chelyabinsk oblast & 0.14247026 & 0.410146977 & -0.267676717 & 0.111 \\
\hline Tyumen oblast & 0.119864862 & 0.030932955 & 0.088931907 & 0.115 \\
\hline
\end{tabular}

We can also claim that the Sverdlovsk oblast has the weakest social immunity, which hinders the territorial economy sustainable development. Also, the territory is exposed to risks of its socio-economic situation deterioration, since the oblast has a number of serious hidden problems in almost all the components of the potentials in question. The Chelyabinsk oblast also possesses a socio-economic genotype that demonstrates higher negative rates of social changes and their bigger influence on the economic activity indicators.

In general, it can be noted that the value of the social immunity core of the Ural region is in the range of $[-0.38 ; 0.09]$. In addition, our observation made on the example of the 
Tyumen oblast is worth noting: if the territory has social immunity, i.e. if its value is positive, then the growth rate of its GRP is higher than that of territories which lack public safety and show low resistance to shocks. This, in turn, confirms our hypothesis that social immunity is one of the sources of sustainable economic development. Another observation of ours fixes the correlation of negative values of social immunity, resulting in its absence, with the GRP shortfall, since the growth rate of this indicator was stable at the same level and increased insignificantly during the entire time period of observation.

\section{Conclusion}

Within the framework of this paper, we put forward the hypothesis that social immunity of the region is one of the sources of its sustainable economic development. To prove the hypothesis, a universal method was developed for assessing social immunity, taking into account the impact of the state of society parameters on the economic development of its territories. This methodology was tested on the example of the Ural regions of one federal district. The research resulted in identifying the territory with social immunity, which demonstrated sustainable GRP growth during the period from 2010 to 2018. It was also found that the lack of social immunity in the region leads to a shortage of economic effects received by its economic entities and the exposure of the territory to economic destabilizing external influences, which are both random and natural. Having identified the trends, we can state that our hypothesis has been proven. To obtain more reliable results we will continue our research and cover more territories, while testing the developed assessment methodology and establishing the dependence of sustainable economic development trends on social processes.

\section{Acknowledgements}

The study was carried out with the financial support of the Russian Foundation for Basic Research within the framework of scientific project No. 18-010-00802 "Modeling the basic code of the regional economy industrial development, taking into account its genetic profile."

\section{References}

1. N. Luhmann, Introduction to Systems Theory, 25 (2007)

2. P.Sztompka, Sociological Research, 2 (2001)

3. R.S. Grinberg, A. Ya. Rubinstein, Economic inequality: current practice and modern theory, 12 (2006)

4. E. Erickson, Identity: Youth and Crisis, 58 (1996)

5. A. Tatarkin, Vestnik OSU, 150 (2003)

6. S.G., Vazhenin, I.S. Vazhenina, Regional Economy, 1 (2012)

7. V.L.Bersenev, Regional Economy, 223 (2012)

8. A. G. Aganbegyan, Socio-Economic Development of Russia, 185 (2004)

9. T.M. Efremova, National J. of Social Work, 35 (2009)

10. P. Romer, J. of Political Economy, 83 (1990) 